\section{CASE OF ARTHRITIC PURPURA.}

By F. ERNEST PEAKE, M.R.C.S., L.R.C.P., Bristol.

THE patient-a well-nourished, healthy female, aged 23, of a slightly neurotic temperament-had always enjoyed good health, and, apart from the ordinary infantile diseases, had never occasion to consult a medical man.

For some time she had been somewhat fastidious in her diet, often preferring sweets to meat and vegetables, but had not abstained from animal and vegetable food to any extent. There was no previous or family history of rheumatism.

On May 21st, when I first saw her, she was suffering from a general erythematous rash, resembling that of scarlet fever. The temperature was $99^{\circ}$. There was no vomiting and no sore throat. The rash entirely disappeared in two days. She then complained of pains in both knee-joints and muscular pains in the legs. The joints were not swollen, but very tender on palpation. She could not stand owing to the pains. The pulse and temperature were normal, and no relief was obtained from the administration of sodium salicylate.

On May 25th she had a severe attack of vomiting, the vomit being distinctly "coffee-ground." This was soon followed by melæna, the evacuations being frequent, liquid, of a darkish red colour, and practically nothing but blood. Pain and tenderness were complained of in the epigastric region and slightly over the abdomen generally. Menstruation occurred on the same day, which was stated to be about the periodical time for its appearance. The discharge was not excessive. Following the vomiting the patient was exceedingly prostrated, the pulse was weak and thready, and varied from 130 to 150 per minute. The temperature was slightly raised, but never exceeded $10^{\circ} \mathrm{F}$.

Nourishment was administered by means of enemata, in each of which was given half-drachm doses of liquor calcii chloridi.

The following day, May 26th, a thick petechial rash appeared on the legs and-to a slighter degree-on the forearms. On the dorsal surface of both feet, the buttocks, and both elbows larger exts avasations occurred, forming blebs, varying in size from a small pea to a threepenny piece. The gums were not swollen, and did not bleed, but purpuric patches appeared on the mucous surface of the lower lip and on the gums. The pain in the knee-joints still continued, both elbow-joints-and particularly the right shoulder-jointbecame affected, and she was unable to raise the right arm from the bed. Flexion of the forearm could only be effected with difficulty and great pain. Pressure of the bedclothes on the legs was also complained of

The hæmatemesis and melæna stopped soon after the appearance of the purpuric rash, and no fresh eruption occurred subsequently. There was no hæmaturia, and no albumen was present in the urine. There were no retinal hæmorrhages.

After the first twenty-four hours the enemata were usually well retained; the purpuric patches, undergoing the usual changes, gradually died away, except on the buttocks and elbows, where, owing to the constant pressure on these parts, the blebs broke, leaving small sores, which soon healed under boracic ointment, the pressure being relieved by pads of cotton wool. Sloughing followed the eruption on the lower lip, leaving a clean, raw surface.

The pains in the joints gradually disappeared. Nourishment by mouth was carefully made to take the place of the rectal feeding, and the patient eventually made a good recovery without a relapse.

\section{THE VALUE OF STERILISED MILK.}

\section{Bx J. KINGSTON BARTON, M.R.C.P.Lond.,} Late Surgeon to the Kensington Dispensary.

DURING the past year there have been the most conflicting statements concerning the virtues and vices of sterilised milk. The scientific chemists state that heated milk has lost many of its nourishing qualities, and of late they state the destruction of pathogenic bacteria includes the slaughter of many most beneficent micro-organisms. Medical men, having seen the enormous saving of infant life since the introduction of sterilised milk, will take the opposite view to the scientists.

Having devoted special attention to this matter during the past two years, I would venture to make. several positive statements :

1. Completely sterilised milk, if administered without any fresh food, will undoubtedly sooner or later produce scurvy.

2. Comparatively or temporarily sterilised milk may be administered for any length of time without fear of scurvy appearing.

3. Completely sterilised milk, if administered at once in perfectly clean bottles, spoons, or cups, can be relied upon as free from any pathogenic bacteria.

4. The heating of milk alters very slightly, if at all, its nourishing qualities.

5. All kinds of sterilised milk, if free from added chemicals, can become foul as quickly, if not quicker, than ordinary fresh milk.

6. All sterilised milk that is put into hermetically sealed vessels, and which can keep fresh in them for several or many days, will produce scurvy unless some fresh food is administered daily; one meal of fresh whey daily will achieve this in younger infants than those who may have fresh vegetables, meat, or fruit.

7. Milk that is raised to the boiling point, or better, to within two degrees of the boiling point, and maintained there five to fifteen minutes is "comparatively" sterilised, and will never produce scurvy, and is almost quite safe from pathogenic organisms.

Paragraphs 6 and 7 are merely extensions of $x$ and 2. If milk is placed in a china vessel which stands in another vessel containing cold water, and this is brought to the boiling point, then the milk will not itself boil within the first fifteen minutes after the water boils. This heated milk does not lose its antiscorbutic properties for at least twelve hours. I cannot state what is the longest period it might retain its antiscorbutic properties, because such kept milk would be otherwise dangerous to give to a child.

Milk that is boiled direct over the fire undoubtedly constipates; but milk that has water placed between it and the fire does not produce this trouble. The only chemical permissible is a small quantity of bicarbonate of soda to be added to the fresh milk before it is scalded. This is to neutralise the acidity which appears in cow's milk soon after it is drawn from the cow, and in the second place the saline seems to produce increase in flow of bile.

To sum up, if you would steer clear of scurvy and avoid pathogenic microbes, then obtain as clean fresh cow's milk as possible twice a day in winter, three times a day in summer, and scald it soon after its receipt, of course every precaution being taken to prevent contamination of the scalded milk between the time of its sterilisation and administration.

As to the strength of milk and water, etc., to give hand-fed infants, that is altogether too wide a discussion to enter upon here. I wish merely to answer the question of how to avoid scurvy.

\section{THE OCCURRENCE OF ZONA BELOW THE KNEE.}

[Since the publication of Dr. Mahon's paper in the British MEDICAL Journal for November 7 th, 1896, p. 1379), we have received notes of the following examples of herpes zoster occurring below the knee.]

\section{I.-A. SYmons Eccles, M.B.,} London.

E. S. E., aged 25, on October I9th, 1896 , took a long night journey of seven hours by train, and owing to the absence of foot warmers could not keep warm below the knees. On arriving at his destination he felt very cold, but a sharp. walk restored the sense of warmth. On the following night he slept in a bed which had not been occupied for some time. and on October 2ist and 22nd he experienced some pain and stiffness in both shoulders and knees.

On October 26th a crop of shingles appeared over the 